\title{
A standardized extract of Ginkgo biloba prevents locomotion impairment induced by cassava juice in Wistar
}

\section{rats}

\section{Eduardo Rivadeneyra-Domínguez ${ }^{1}{ }^{*}$, Alma Vázquez-Luna ${ }^{1,2}$, Juan F. Rodríguez-Landa ${ }^{1,3}$ and Rafael Díaz-Sobac ${ }^{1,2}$}

${ }^{1}$ Laboratorio de Farmacotoxicología, Facultad de Química Farmacéutica Biológica, Universidad Veracruzana, Xalapa, México

${ }^{2}$ Laboratorio de Biología y Química Molecular de Frutas, Instituto de Ciencias Básicas, Universidad Veracruzana, Xalapa, México

${ }^{3}$ Laboratorio de Neurofarmacologia, Instituto de Neuroetología, Universidad Veracruzana, Xalapa, México

\section{Edited by:}

Andrew C. McCreary, Brains On-Line,

Netherlands

\section{Reviewed by:}

Li Zhang, National Institute on Alcohol Abuse and Alcoholism - National Institutes of Health, USA Harry Wilhelm Maria Steinbusch, Maastricht University, Netherlands

\section{*Correspondence:}

Eduardo Rivadeneyra-Domínguez, Laboratorio de Farmacotoxicología, Facultad de Química Farmacéutica Biológica, Universidad Veracruzana, Circuito Dr. Gonzalo Aguirre Beltrán s/n, Zona Universitaria, Xalapa 91000, México

e-mail: edrivadeneyra@uv.mx
The long-term consumption of cassava (Manihot esculenta Crantz) juice produce neurotoxic effects in the rat, characterized by an increased motor activity in the open field test and presence of uncoordinated swim (i.e., lateral swimming), in the swim test; which has been associated with damage in the hippocampus (CA1). On the other hand, flavonoids content in the Ginkgo biloba extract has been reported to produces neuroprotective effects at experimental level; therefore we hypothesized that G. biloba extract may prevents the motor alterations produced by cassava juice and reduce cellular damage in hippocampal neurons of the rat. In present study the effect of vehicle, cassava juice (linamarin, $0.30 \mathrm{mg} / \mathrm{kg}$ ), G. biloba extract (dry extract, $160 \mathrm{mg} / \mathrm{kg}$ ), and combination of treatment were evaluated in the open field and swim tests to identify locomotor and hippocampal alterations in adult male Wistar rats. All treatments were administered once per day, every $24 \mathrm{~h}$, for 28 days, by oral rout. The effect was evaluated at $0,7,14,21$, and 28 days of treatment. The results show that cassava group from day 14 of treatment increase crossing and rearing in the open field test, as compared with the vehicle group; while in the swim test produces an uncoordinated swim characterized by the lateral swim. In this same group an increase in the number of damage neurons in the hippocampus (CA1) was identified. Interestingly, both behavioral and neuronal alterations produced by cassava juice administration were prevented by treatment with G. biloba extract. The results shown that G. biloba extract exert a protective effect against behavioral and neuronal damage associated with consumption of cassava juice in the rat. These effects are possibly related with flavonoid content in the G. biloba extract.

Keywords: Manihot esculenta Crantz, Cassava, neurotoxic, hippocampus, locomotor activity, Ginkgo biloba

\section{INTRODUCTION}

One of the main food for human beings are tubers and roots, due to its simplicity of production, easy storage of their derivates and the relative stability of the chemical compounds. The potato and cassava are the most important edible tubers because of its high carbohydrate content. Cassava root is usually consumed fresh, or processed as flour, some populations of Africa and America also consume leaves due to its medicinal properties (FAO and WHO, 2009; Rivadeneyra-Domínguez et al., 2013). However, cassava contains cyanogenic glycosides (linamarin and lotaustralin) which through hydrolysis produce cyanohydrin and glucose, and it is metabolized into acetone and hydrocyanic acid free. This metabolic process produces toxicity in the organism when it reaches concentrations above $100 \mu \mathrm{g}$ (Ceballos and de la Cruz, 2002; Sornyotha et al., 2007).

Excessive consumption of cassava, an inappropriate processing and a low protein diet has been associated with neurodegenerative and neurological diseases such as lathyrism, hypothyroidism, Konzo, and Tropical Ataxic Neuropathy (TAN; Zaninovic, 2003;
FAO and WHO, 2009). Furthermore, has been reported significant damage in brain structures involved in motor and cognitive integration including thalamic nuclei, piriform cortex, ventral nuclei, paraventricular area, and hippocampus, among others. In a previous study, Rivadeneyra-Domínguez et al. (2013) was reported that treated rats with cassava juice, in which linamarin was identified, shown alterations in motor incoordination (i.e., an increase in the lateral swimming) when they were evaluated to the swim test; which evidenced the neurotoxic effects associated probably with linamarin contained in the cassava juice.

On the other hand, Ginkgo biloba contains bioactive constituents mainly flavonoids (i.e., quercetin, kaempferol, and isorhamnetin), some diterpene trilactones such as ginkgolide A, $\mathrm{B}$, and $\mathrm{C}$ sesquiterpene trilactonic, bilobalide, and proanthocyanidins (Koltermann et al., 2007), among others. Kaempferol and quercetin contained in G. biloba extracts are involved in the neuroprotective effects identified in vivo studies. Also it has been found that the neuroprotective effect of G. biloba extracts against excitotoxicity-induced damage associated with the overactivation 
of $N$-methyl-D-aspartate receptors, is associated with the high content of flavonoids and some sesquiterpenelactones. Additionally, flavonoids possess antioxidant activity, inhibiting the formation of hydroxyl and adriamicil radicals; reducing the lipid peroxidation (Pincemail et al., 1989; Filoteo et al., 1997; Xiao et al., 2006).

Ginkgo biloba extract also reduces neuroinflammation process; improves memory, learning, and cognitive function through a lower loss of muscarinic and $\alpha$-adrenergic receptors. Additionally, G. biloba extracts increase the levels of choline acetyltransferase and somatostatin, in the cerebral cortex and some hippocampus regions (Tang et al., 2002; Spencer, 2009). Because G. biloba extract may exert neuroprotective effects in some brain structures, including hippocampus (Ying-Shan et al., 2000; Ahlemeyer and Krieglstein, 2003), and long-term consumption of cassava juice (Manihot esculenta Crantz) produces motor incoordination apparently associated with neurotoxic effects of linamarin contained in it, we hypothesized that the treatment with a $G$. biloba extract prevents motor incoordination in rats subjected to the swim test, and additionally reduces the neuronal damage in the hippocampus CA1 area.

\section{MATERIALS AND METHODS BIOLOGICAL MATERIAL}

Cassava tubers (M. esculenta Crantz), free of agrochemicals, were collected from a traditional cultivation in the town of Defensa, Yecuatla county, Veracruz State, México (latitude19 $52^{\prime} 00^{\prime \prime} \mathrm{N}$, longitude $96^{\circ} 47^{\prime} 00^{\prime \prime} \mathrm{W}$ ) at an altitude $260 \mathrm{~m}$ above sea level (INEGI, 2010). The biological material was authenticated by professional staff who specialize in taxonomy from the Herbarium XAL at the Institute of Ecology A.C. (INECOL) in Xalapa, Veracruz, México.

\section{CASSAVA JUICE}

Preparation cassava juice was performed according to procedures described in previous studies (Rivadeneyra-Domínguez et al., 2013). To avoid any degradation process, the cassava juice was freshly prepared every day before administration. Tubers were washed just after collection. They were peeled and cut into approximately $5 \mathrm{~cm} \times 2 \mathrm{~cm} \times 2 \mathrm{~cm}$ pieces. To standardize and facilitate the doses administered, the juice of the tuber was obtained with a juice extractor machine (Moulinex Model Centri III, Celaya, Guanajuato, México) and immediately administered per os to the rats.

\section{STANDARDIZED EXTRACT OF Ginkgo biloba}

Dry standardized extract of G. biloba (Pharmaceutical presentation, VASODIL ${ }^{\circledR}$, Laboratorios ALTANA Pharma, México) was used. It contains dry extract of G. biloba $40 \mathrm{mg} / \mathrm{mL}$ and $9.6 \mathrm{mg}$ of standardized flavones glycosides calculated as quercetin and kaempferol. The used dose in present investigation was $160 \mathrm{mg} / \mathrm{Kg}$ of the rats' weight.

\section{ANIMALS, EXPERIMENTAL GROUPS, AND TREATMENTS}

Thirty-two adult male Wistar rats, weighing 250-300 g, were obtained from the vivarium of the Facultad de Medicina, Universidad Veracruzana, Xalapa, Veracruz, México. The rats were housed eight per cage in Plexiglas cages, with a $12 \mathrm{~h} / 12 \mathrm{~h}$ light/dark cycle (lights on at 7:00 AM) and average room temperature of $25 \pm 1^{\circ} \mathrm{C}$. The animals had ad libitum access to water and food. All of the experimental procedures were performed according to the Guide for the Care and Use of Laboratory Animals (National Research Council, 1996) and the Norma Oficial Mexicana para el Uso y Cuidado de Animales de Laboratorio (Norma Oficial Mexicana, NOM-062-ZOO, 1999). All efforts were made to minimize animal discomfort during the course of this investigation.

A longitudinal study with four independent groups $(n=8$ rats per group) was performed: a control group received vehicle of G. biloba extract plus vehicle of cassava juice, a second group received vehicle of $G$. biloba extract plus cassava juice, a third group received G. biloba extract plus vehicle of cassava juice, and the last group received G. biloba extract plus cassava juice. The vehicle or the extract of G. biloba was administered in an equivalent volume of $2 \mathrm{~mL} / \mathrm{Kg}$ of the rats' weights by oral rout (PO); containing $160 \mathrm{mg} / 2 \mathrm{~mL}$ of standardized extract of G. biloba. The vehicle or the juice of cassava was administered 30 min after administration of vehicle or extract of G. biloba, by PO in an equivalent volume of $2 \mathrm{~mL} / \mathrm{Kg}$ of the rats' weights, containing $0.30 \mathrm{mg}$ of linamarin per $2 \mathrm{~mL}$ of cassava juice. All of the treatments were administered once per day, every $24 \mathrm{~h}$, for 28 days through a displaceable sterilized intraesophageal polyethylene cannula $(4 \mathrm{~cm}$ length, $1.0 \mathrm{~mm}$ diameter; S-54-HLCole-Parmer, Vernon Hills, IL, USA) coupled to a disposable syringe (Roger, Chalco, Estado de México, México). In the baseline session (day 0) without treatment, the rats were evaluated in the open field test and subsequently swim test. At the end of this first session, the treatments began. One hour after vehicle or cassava juice administration on days $7,14,21$, and 28 of treatment, the rats were evaluated in the same behavioral tests. After the last swim test (day 28) the rats were perfused and the brains removed for subsequent histological analysis.

\section{BEHAVIORAL TESTS}

All of the open field and swim test sessions were video-recorded. Two independent observers who were blinded to the treatments recorded the dependent variables using custom-designed software until they attained results with a confidence index of at least 95\%.

\section{OPEN FIELD TEST}

The rats were individually placed in an opaque Plexiglas cage $(44 \mathrm{~cm} \times 33 \mathrm{~cm})$ with $20 \mathrm{~cm}$ high walls and the floor divided into 12 squares $(11 \mathrm{~cm} \times 11 \mathrm{~cm})$. The number of crossings and rearings were recorded during a 5 min test. A crossing was scored when a rat passed from one square to another with its hindlimbs. A rearing was considered when the rat assumed a vertical posture, supported by its hindlimbs, with respect to the floor of the box. A crossing was interpreted as an indicator of motor activity, and rearing was used to determine alterations in motor coordination. The swim test was performed after the open field test.

\section{SWIM TEST}

The rats were individually placed in a rectangular pool $(26 \mathrm{~cm} \times 29 \mathrm{~cm} \times 50 \mathrm{~cm})$ filled with water $\left(25 \pm 1^{\circ} \mathrm{C}\right)$, for $5 \mathrm{~min}$. The depth of the water was adjusted so that the rat could 
touch the bottom of the pool with one or both of its hindlimbs and tail. At the beginning of the test, the rat was gently placed in one corner of the pool. The rats swam vigorously as soon as they contacted the water. None of the animals drowned. After this initial swimming behavior, the rats displayed lateral swimming as previously was described (Rivadeneyra-Domínguez et al., 2013). The dependent variable was the number of times that lateral swimming was displayed by the rat in this test. Lateral swimming is operationally defined as behavior in which the rat swims slowly on its side without maintaining its horizontal balance. During this behavior, the rat swims on its right or left side, with its head maintained horizontally. The hindlimbs remain extended and rigid, parallel to the water surface, for short periods of time. The hindlimbs are uncoordinatedly moved to achieve water displacement. One or both forelimbs remain retracted. After this lateral swimming, the rats eventually swim "normally" for short periods of time.

\section{HISTOLOGICAL ANALYSIS Perfusion}

At the end of behavioral tests (day 28 of treatment), the rats received an overdose of sodium pentobarbital (Sedalphorte ${ }^{\circledR}$, Laboratorios Salud y bienestar animal, México) and were perfused transcardially with $200 \mathrm{~mL}$ of saline solution followed by $200 \mathrm{~mL}$ of $4 \%$ paraformaldehyde in $0.1 \mathrm{M}$ phosphate buffer (Temperature $27^{\circ} \mathrm{C}, \mathrm{pH} 8.3$ ). The brains were removed and preserved in $20 \%$ formalin until histological analysis.

\section{Dehydration brain}

The brains were dehydrated in ethanol solutions (70, 80, 96, and $100 \%$ ), cleared in xylene and embedded in paraffin. Serial coronal sections of $10 \mu \mathrm{m}$ thick-sections at the level of the hippocampus: interaural $4.70 \mathrm{~mm}$, Bregma $4.30 \mathrm{~mm}$ (Paxinos and Watson, 1998) were obtained with a vibratome.

\section{Stains and preparation of brain slices}

The brain slices containing the hippocampus were stained with the modified technique of hematoxylin-eosin and dried at room temperature (Lynch et al., 1982; Neira and Sedano, 2008). Posteriorly, the stained brain slices were mounted with Permount for analysis by light microscopy.

\section{Quantification of damaged cells}

Three fields of different slices that included the CA1 area of the right $(\mathrm{Ap}=-3.30$ to $-4.00 \mathrm{~mm}, L=1.2 \mathrm{~mm}$ and $H=3.0 \mathrm{~mm}$ ) or left (Ap $=3.30$ to $-4.00 \mathrm{~mm}, L=-1.2 \mathrm{~mm}$, and $H=3.0 \mathrm{~mm})$ hippocampus with respect to Bregma (Paxinos and Watson, 1998) were analyzed per rat from each group. The number of damaged cells in each experimental group was measured. Neuronal damage was considered when under optical microscope examination the presence of eosinophilic neurons (acidophilic) with nuclear changes characterized by the presence of eosinophilic cytosol and pyknotic or fragmented nuclei were identified; which are indicators of neuronal damage (Neira and Sedano, 2008).

\section{Statistical analysis}

The data from two behavioral tests were analyzed by two-way ANOVA, considering as the first factor treatment, and the second factor days of treatment. Significant differences $(p \leq 0.05)$ in the ANOVA were followed by Student-Newman-Keuls post hoc test. The data from the histological study were analyzed using KruskalWallis one-way ANOVA on Ranks, followed by Tukey post hoc test. All data are expressed as the mean \pm SE for each variable.

\section{RESULTS}

\section{LOCOMOTOR ACTIVITY IN THE OPEN FIELD TEST}

Table 1 shows the results of crossing in the open field test in rats treated with vehicles, cassava juice, G. biloba, or combination of treatments ( $G$. biloba plus cassava juice). The analysis of crossing show significant differences among treatments $[F(3,140)=19.778 ; p<0.001]$, days of treatment $[F(4,140)=10.610 ; p<0.001]$, and interaction between factors $[F(12,140)=2.344 ; p<0.009]$. The post hoc test showed that the vehicle and $G$. biloba treated groups reduce significantly the crossing throughout the experimental sessions. However, in the cassava treated group crossing was reduced in days 7 and 14 of treatment respect to the vehicle treated group, but it was recovered to basal values in days 21 and 28 of treatment. No significant differences were detected in the G. biloba plus cassava juice treated groups along of the experiment.

The analysis of the rearing showed similar results to those obtained in crossing in the open field test; that behavior was affected by treatments $[F(3,140)=13.642 ; p<0.001]$, days of treatment $[F(4,140)=4.712 ; p<0.001]$, but not interaction between factors $[F(12,140)=1.540 ; p=0.117]$ was identified. The post hoc test revealed that the control, G. biloba or G. biloba plus cassava juice groups reduced rearing from day 14 of the treatment until the end of the study, while the group receiving cassava

Table 1 | Number of crossing in the open field test along of days of treatments.

\begin{tabular}{llllll}
\hline Treatment & Basal & Day 7 & Day 14 & Day 21 & Day 28 \\
\hline Control & $44.5 \pm 9.8$ & $37.6 \pm 8.7^{*}$ & $24.5 \pm 3.7^{*}$ & $14.0 \pm 4.49^{*}$ & $16.25 \pm 2.5^{*}$ \\
Cassava juice & $44.5 \pm 9.8$ & $28.6 \pm 4.1$ & $29.1 \pm 7.8$ & $36.75 \pm 5.1^{+}$ & $42 \pm 2.1^{+}$ \\
Ginkgo biloba & $44.5 \pm 9.8$ & $17.3 \pm 3.8^{*}$ & $19.6 \pm 4.5^{*}$ & $8.0 \pm 1.9^{*}$ & $11.0 \pm 3.3^{*}$ \\
Cassava juice + Ginkgo biloba & $44.5 \pm 9.8$ & $14.1 \pm 3.4$ & $13.5 \pm 2.4$ & $11.0 \pm 2.0$ & $16.13 \pm 2.3$
\end{tabular}

The values represent the mean $\pm S E$ of eight rats. ${ }^{*} p<0.05 \mathrm{vs}$ basal of the same group; $+p<0.05 \mathrm{vs}$. all groups in the same day of treatment (two-way ANOVA, post hoc test Student-Newman-Keuls). 


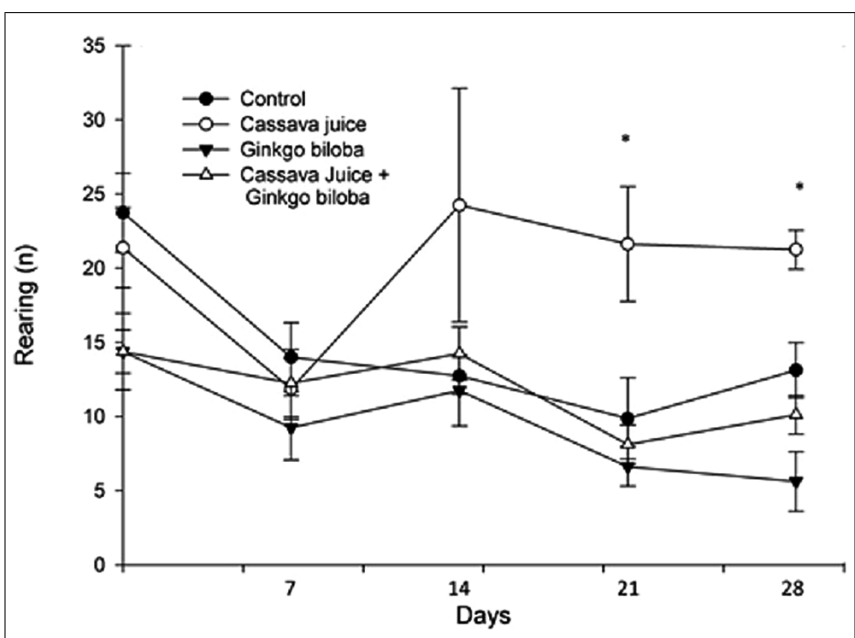

FIGURE 1 | Number of rearing in the open field test. All experimental groups, except cassava juice group reduced rearing from day 14 of treatment respect to the basal values of the same group. ${ }^{*} p<0.05$ vs all groups in the same day of treatment. (two-way ANOVA, post hoc test Student-Newman-Keuls)

juice treatment reduced rearing on day 7 days of treatment compared to the basal; but it was recovered to the basal values from day 14 of treatment (Figure 1).

\section{SWIM TEST}

The analysis of the number of lateral swim showed significant differences considering treatments $[F(3,149)=237.654$; $p<0.001]$, days of treatments $[F(4,149)=24.256 ; p<0.001]$, and in the interaction of factors $[F(12,149)=24.332$; $p<0.001]$. The post hoc test revealed that rats control or treated with $G$. biloba did not presented lateral swimming along of the days of treatment. However, rats that consume cassava juice showed an increase in the number of lateral swim from day 7 of treatment and this effect being more accentuated at 28 day of treatment. Interestingly, this effect was no detected in the $G$. biloba plus cassava juice group (Figure 2).

\section{DAMAGED NEURONS IN CA1 AREA OF THE HIPPOCAMPUS}

Figure 3 show a representative photograph of CA1 hippocampus damage neurons in each treatment group. The analysis of the damage neurons in this area did not revealed significant differences among left or right side, therefore all neurons were including together as CA1 hippocampus area. The analysis of the number of damaged neurons in the CA1 area of hippocampus from different groups of treatment showed significant differences $\left[H_{(3)}=26.121 ; p<0.001\right]$. The post hoc test showed that cassava juice-treated group had the higher number $(13.75 \pm 1.90)$ of damaged neurons $(p<0.05)$, as compared with the others groups: control (0.50 \pm 0.18$)$, G. biloba $(0.62 \pm 0.18)$ and $G$. biloba plus cassava juice (3.00 \pm 0.46). As showed the results $G$. biloba treatment prevents the neuronal damage associated with cassava juice treatment.

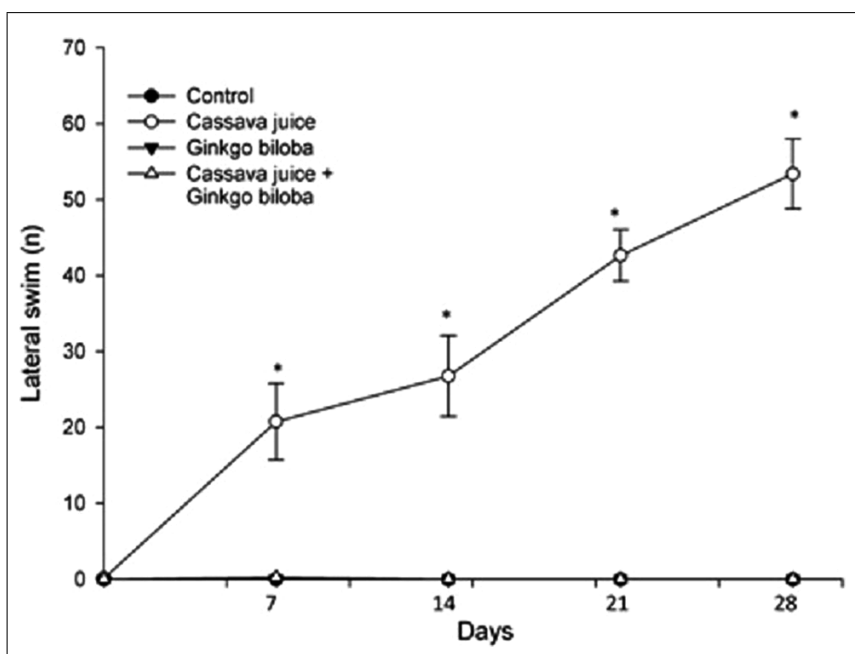

FIGURE 2 | Number of lateral swim. This behavior was only detected in the cassava juice treated group, an effect prevented by simultaneous administration of Ginkgo biloba extract. ${ }^{*} p<0.05$ vs basal and all groups in the same day of treatment. (two-way ANOVA, post hoc test Student-Newman-Keuls).

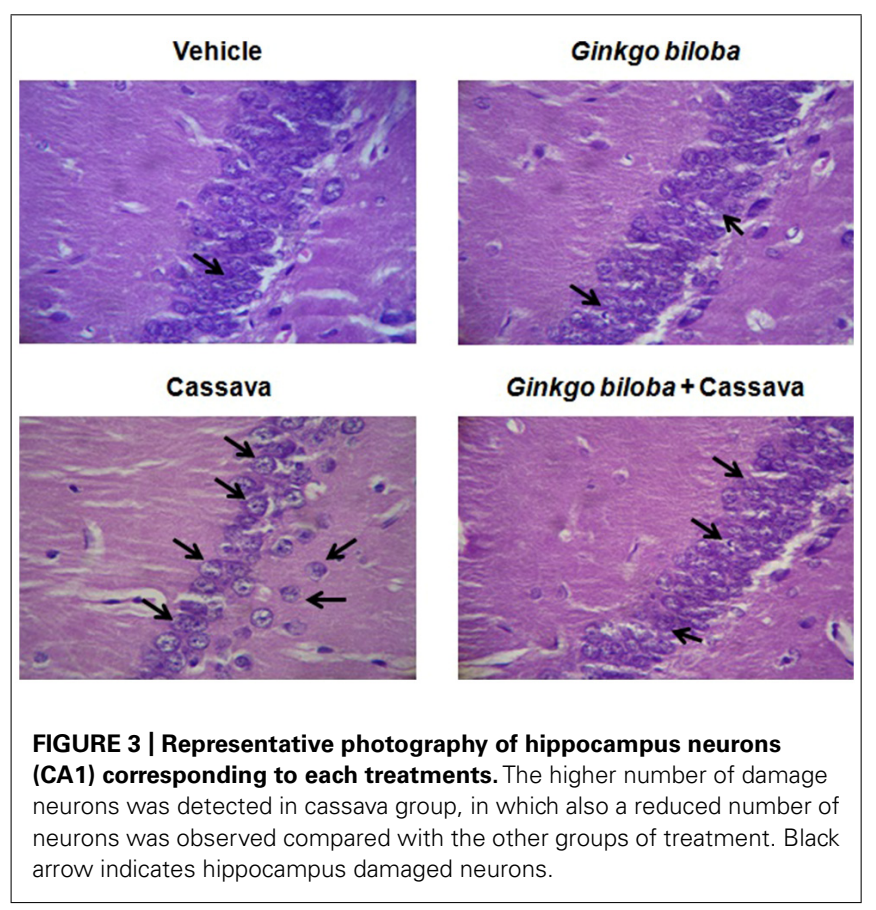

\section{DISCUSSION}

The open field test is widely used to detect changes in locomotor activity, associated with experimental manipulations or drug administrations (i.e., hyperactivity, hypoactivity, or not changes associated with drug treatment). Repeated session in the open field test induces habituation in the animals, reducing crossing in subsequently session respect to basal session (Brudzynski and Krol, 1997). In the present study, the control, G. biloba, and G. biloba plus cassava juice groups, decreased locomotor activity in the open field along the experimental sessions, which is in accordance with 
previous reports (Spencer, 2009), considering the common habituation to this test after repeated sessions. Contrarily, the cassava juice group initially reduced crossing, but from day 14 of treatment crossing returned to basal values, which could be related with the neurotoxic effects produced by linamarin contained in the cassava juice as previously reported (Rivadeneyra-Domínguez et al., 2013). The fact that the G. biloba plus cassava juice group had a gradual reduction of crossing along of the experiment similarly to the control group, suggest a protective effect of $G$. biloba extract against the toxic effects produced by cassava juice identified by changes on the motor activity. Present result may be supported by the neuroprotective effects of $G$. biloba extracts previously reported (Pincemail et al., 1989; Filoteo et al., 1997; Xiao et al., 2006; Spencer, 2009). Respect to rearing in the open field also was gradually reduced along of experimental session as previous reports (Rivadeneyra-Domínguez et al., 2009, 2013; Saavedra et al., 2011), which is associated with an adaptive effect by the repetition of the test. However, rats treated with cassava juice on day 21 and 28 of treatment increasing this behavior respect to the other experimental groups. This effect support the motor alterations in the cassava treated group, and the protective effect of G. biloba, considering that group with the extract of this plant plus cassava juice did not increase rearing as cassava juice do it.

In present investigation, cassava juice treatment produced locomotor incoordination in the swim test, represented by lateral swimming. In a previous study was reported that long-term consumption of cassava juice (Rivadeneyra-Domínguez et al., 2013) or Dioon spinulosum seeds, induced motor alterations characterized by lateral swimming or rotational behavior in the swim test (Rivadeneyra-Domínguez et al., 2009) which was associated with the content of linamarin or neurotoxic methylazoxymethanol (MAM), respectively. Interestingly, when MAM was microinjected into the hippocampal (CA1) of the rat, a motor incoordination in the swim test was observed (Saavedra et al., 2011). These results, shown that hippocampus participate in the locomotor alterations induced by neurotoxic compounds of some plants.

Among the diseases associated with cassava consumption are TAN and Konzo, which are mainly characterized by paraparesis of the lower or upper extremities, ataxia, muscle weakness, and motor alterations (Tylleskär, 1994; Peterson et al., 1995; Zaninovic, 2003; FAO and WHO, 2009). Therefore it could be related with motor alterations observed in rats treated with cassava juice; which was prevented by coadministration of $G$. biloba extract in present investigation. We report a toxic effect on motor activity in rats treated with cassava juice and is suggested that this effect could be related with chemical compounds contained in the plant; however it is necessary to realize additional specific studies to identify or discard other toxics effect on muscle stiffness, respiratory, cardiovascular, digestive, metabolic systems and cancer that could occur under long-term cassava consumption.

Previous studies have reported that $G$. biloba extract reduces neuronal damage caused by intoxication with methyl parathion and preserve cellular organization of the cerebellum granular layer in the rat (Cárdenas et al., 2010). In present study cassava juice group had a high number of damaged cells in the hippocampus (CA1), which was not detected in G. biloba plus cassava juice group. Aforementioned, suggests a neuroprotective effect of $G$. biloba extract on hippocampal neurons, probably associated with a reduction of excitotoxicity on NMDA receptors; however, specific studies are required to clarify this propose. The effect of flavonoids on the brain and cellular function include neuroprotection, reduction of neuroinflammation and improve memory, learning, and cognitive function (Mu et al., 2007). Additionally, flavonoids contribute to permeability, nutrition, oxygen uptake, and ATP synthesis (Mahadevan and Park, 2008). Flavonoids from G. biloba extract produces antioxidant activity and neutralizes free oxygen and hydroxyl radicals increased during cerebral damage followed of the ischemia (Blecharz-Klin et al., 2009). Although present study did not explored the cellular mechanism involved in the hippocampal neuronal damage produced by cassava juice nor the apparent protective effect of the G. biloba extract, the results suggests that evaluated extract produces a neuroprotective effect in hippocampal cells against toxic compounds contained in cassava juice, which must be explored in future studies. However present results, suggest that hippocampus could participate in motor alterations detected in cassava treated group, which may be support by previous studies in which microinjection of neurotoxic chemical compounds isolated from cycads (Saavedra et al., 2011), produces motor alterations in the rat, similar to detected in cassava treated rats.

Finally, although the precise mechanisms underlying the protective effect of $G$. biloba extract has not been explored in this study, it may be associated with the flavonoid content in the $G$. biloba extract (Ahlemeyer and Krieglstein, 2003). In this way, there is evidence that flavonoids content in the G. biloba extract may prevent excitotoxicity induced by NMDA receptor stimulation. This is relevant, considering that some toxic compounds contained in cassava juice can contribute to the overactivation of NMDA receptors (Spencer, 2009), causing neurotoxic effect. Therefore, it suggests that $G$. biloba extract may have protective activity against toxic effects produced by chemical compounds contained in cassava juice and consequently prevents locomotion impairments in the rats.

\section{CONCLUSION}

The long-term consumption of cassava juice produced locomotion impairment probably associated with neuronal damage in the hippocampus (CA1), which is attenuated by G. biloba extract in Wistar rats.

\section{REFERENCES}

Ahlemeyer, B., and Krieglstein, J. (2003). Neuroprotective effects of Ginkgo biloba extract. Cell. Mol. Life Sci. 60, 1779-1772. doi: 10.1007/s00018-003-3080-1

Blecharz-Klin, K., Piechal, A., Joniec, I., Pyrzanowska, J., and Widy-Tyszkiewicz, E. (2009). Pharmacological and biochemical effects of Ginkgo biloba extract on learning, memory consolidation and motor activity in old rats. Acta Neurobiol. Exp. 69, 217-231.

Brudzynski, S. M., and Krol, S. (1997). Analysis of locomotor activity in the rat: parallelism. Index, a new measure of locomotor exploratory pattern. Physiol. Behav. 62, 635-642. doi: 10.1016/S0031-9384(97)00189-3

Cárdenas, J. M., Martínez, M. C., Jaramillo, F., Rodríguez-Vázquez, M. L., GutierrezCantú, F., Posadas, F. A., et al. (2010). Efecto protector del Ginkgo biloba en el daño inducido por el paratión metílico en células de la capa granulosa del cerebelo en ratas. Rev. Mex. Cien. Farm. 41, 37-42.

Ceballos, H., and de la Cruz, G. A. (2002). "Taxonomía y morfología de la yuca," in La Yuca en el Tercer Milenio. Sistemas Modernos de Producción, Procesamiento, 
Utilización y Comercialización, CIAT No. 327, eds B. Opsina and H. Ceballos, (Cali: International Center for Tropical Agriculture), 17-33.

FAO and WHO. (2009). Comisión del Codex Alimentarus. Programa Conjunto Sobre Normas Alimentarias Comité del Codex Sobre Contaminantes de Los Alimentos. San Diego, CA: Food and Agriculture Organization of the United Nations and World Health Organization, 7-9.

Filoteo, J. V., Rilling, L. M., Cole, B., Williams, B. J., Davis, J. D., and Roberts, J. W. (1997). Variable memory profiles in Parkinson's disease. J. Clin. Exp. Neuropsychol. 19, 878-88. doi: 10.1080/0168863970840E3768

INEGI. (2010). Anuario Estadístico de Veracruz de Ignacio de la Llave. México City: Instituto Nacional de Estadística y Geografía.

Koltermann, A., Hartkorn, A., Koch, E., Fürst, R., Vollmar, A. M., and Zahler, S. (2007). Ginkgo biloba extract EGb 761 increases endothelial nitric oxide production in vitro and in vivo. Cell. Mol. Life Sci. 64, 1715-1722. doi: 10.1007/s00018-007-7085-z

Lynch, M. J., Raphael, S. S., Mellor, L. D., Spare, P. D., and Inwood, M. J. H. (1982). Métodos de Laboratorio, 2nd Edn. México city: Editorial Interamericana, 1099-1190.

Mahadevan, S., and Park, Y. (2008). Multifaceted therapeutic benefits of Ginkgo biloba L.: chemistry, efficacy, safety, and uses. J. Food Sci. 73, R14-R19. doi: 10.1111/j.1750-3841.2007.00597.x

$\mathrm{Mu}$, L., Kou, J., Zhu, D., and Yu, B. (2007). Comparison of neuroprotective effects of flavonoids, terpenoids and their combination from Ginkgo biloba on Ischemia-Reperfusion-Injured Mice. Pharm. Biol. 45, 728-733. doi: 10.1080/13880200701575486

National Research Council. (1996). Guide for the Care and Use of Laboratory Animals. A Report of the Institute of Laboratory Animal Resource Committee on the Care and Use of Laboratory Animals, NIH Publication No. 85-23. Washington, DC: U.S. Department of health and human Services.

Neira, M. C., and Sedano, G. E. (2008). Histología, Técnicas Microscópicas. Lima: Departamento Académico de Ciencias Morfológicas, Facultad de Medicina, Universidad Mayor de San Marcos, 5-17.

Norma Oficial Mexicana, NOM-062-ZOO. (1999). Especificaciones Técnicas para la Producción, Cuidado y Uso de los Animales de Laboratorio. México city: Secretaría de Agricultura, Ganadería, Desarrollo Rural, Pesca y Alimentación.

Paxinos, G., and Watson, C. (1998). The Rat Brain in Stereotaxic Coordinates, Compact 4th Edn. San Diego, CA: Academic press.

Peterson, S. M., Légue, F., Tyllerkäir, T., Kpizingui, E., and Rosling, H. (1995). Improved cassava-processing can help reduce iodine deficiency disorders in the Central African Republic. Nutr. Res. 15, 803-812. doi: 10.1016/02715317(95)00046-L

Pincemail, J., Dupuis, M., Nasr, C., Hans, P., Haag-Beurrier, M., and Anton R. (1989). Superoxide anion scavenging effect and superoxide dismutase activity of Ginkgo biloba extract. Experientia 45, 708-712. doi: 10.1007/ BF01974564

Rivadeneyra-Domínguez, E., Saavedra, M., and Rodríguez-Landa, J. F. (2009). El tratamiento con progesterona previene las alteraciones motoras inducidas por la intoxicación de semillas de cícada (Dioon spinulosum) en las ratas macho. Rev. Toxicol. 26, 117-121.
Rivadeneyra-Domínguez, E., Vázquez-Luna, A., Rodríguez-Landa, J. F., and DíazSobac, R. (2013). Neurotoxic effect of linamarin in rats associated with cassava (Manihot esculenta Crantz) consumption. Food Chem. Toxicol. 59, 230-235. doi: 10.1016/j.fct.2013.06.004

Saavedra, M., Rivadeneyra-Domínguez, E., and Rodríguez-Landa, J. F. (2011). Alteraciones motoras inducidas por la microinyección Intrahipocampal de Metilazoximetanol en ratas macho forzadas a nadar. Arch Neuroci. 16, $186-192$.

Sornyotha, S., Lay Kyu, K., and Ratanakhanokchai, K. (2007). Purification and detection of linamarin from cassava root cortex by high performance liquid chromatograpy. Food Chem. 104, 1750-1754. doi: 10.1016/j.foodchem.2006.10.071

Spencer, J. P. (2009). Flavonoids and brain health: multiple effects underpinned by common mechanisms. Genes Nutr. 4, 243-250. doi: 10.1007/s12263-009-0136-3

Tang, F., Nag, S., Shiu, S. Y., and Pang, S. F. (2002). The effects of melatonin and Ginkgo biloba extract on memory loss and choline acetyltransferase activities in the brain of rats infused intracerebroventricularly with beta-amyloid. Life Sci. 71, 2625-2631. doi: 10.1016/S0024-3205(02)02105-7

Tylleskär, T. (1994). The Causation of Konzo. Studies on Paralytic Disease in Africa. Acta Universitations Upsaliensis Comprhensive Summaries of Uppsala Dissertations from the Faculty of Medicine, Uppsala, 413-467.

Xiao, Z. Y., Sun, C. K., Xiao, X. W., Lin, Y. Z., Li, S., Ma, H., et al. (2006). Effects of Ginkgo biloba extract against excitotoxicity induced by NMDA receptors and mechanism thereof. Zhonghua Yi Xue Za Zchi 86, 2479-2484.

Ying-Shan, H., Wen-Hua, Z., Bastianetto, S., Yean-Guy, Ch., and Quirion, R. (2000). The Ginkgo biloba extract (Egb 761) protects and rescues hippocampal cells against nitric oxide-induced toxicity: involvement of its flavonoid constituents nad protein kinase C. J. Neurochem. 74, 2268-2277. doi: 10.1038/sj.bjp.0705688

Zaninovic, V. M. D. (2003). Posible asociación de algunas enfermedades neurológicas con el consume excesivo de la yuca mal procesada y de otros vegetales neurotóxicos. Colomb. Med. 34, 82-91.

Conflict of Interest Statement: The authors declare that the research was conducted in the absence of any commercial or financial relationships that could be construed as a potential conflict of interest.

Received: 03 May 2014; accepted: 02 September 2014; published online: 25 September 2014.

Citation: Rivadeneyra-Domínguez E, Vázquez-Luna A, Rodríguez-Landa JF and Díaz-Sobac R (2014) A standardized extract of Ginkgo biloba prevents locomotion impairment induced by cassava juice in Wistar rats. Front. Pharmacol. 5:213. doi: 10.3389/fphar.2014.00213

This article was submitted to Neuropharmacology, a section of the journal Frontiers in Pharmacology.

Copyright (c) 2014 Rivadeneyra-Domínguez, Vázquez-Luna, Rodríguez-Landa and Diaz-Sobac. This is an open-access article distributed under the terms of the Creative Commons Attribution License (CC BY). The use, distribution or reproduction in other forums is permitted, provided the original author(s) or licensor are credited and that the original publication in this journal is cited, in accordance with accepted academic practice. No use, distribution or reproduction is permitted which does not comply with these terms. 